\title{
REFLEXÕES NECESSÁRIAS E URGENTES ACERCA DA GESTÃO DA EAD NO BRASIL
}

\author{
Marcello Ferreira ${ }^{1}$ \\ Universidade de Brasília \\ http://orcid.org/ 0000-0003-4945-3169 \\ Marcos Rogério Martins Costa ${ }^{2}$ \\ Universidade de Brasília \\ http://orcid.org/0000-0002-4627-9989 \\ Daniel Mill ${ }^{3}$ \\ Universidade Federal de São Carlos \\ http://orcid.org/0000-0002-8336-3645
}

\section{RESUMO}

Desde a década de 1990, o desenvolvimento e a amplificação de Tecnologias Digitais da Informação e Comunicação (TDIC) em processos educacionais é um fenômeno mundial, certamente associado aos avanços de modelos compreensivos da cognição humana na cultura digital, mas, sobretudo, imbricado à totalidade econômica de matriz neoliberal. Os imperativos de distanciamento social vinculados à pandemia de Covid-19, deflagrada em 2020, catalisaram formas diversificadas de ensino não presencial no Brasil, inclusive na Educação Básica. Observando os respectivos impactos, mas, sobretudo, suas determinações, objetiva-se discutir a gestão de uma de suas formas peculiares - a Educação a Distância (EaD) -, buscando apontar categorias e reflexões que possam explicar e contradizer práticas associadas, sejam elas tradicionalizadas, sejam elas contingenciais. Dentre os variados aspectos estruturais e pedagógicos a que $\mathrm{EaD}$ se relaciona, detém-se nesta discussão aos elementos da gestão que mobilizem, no modelo brasileiro, a implantação de processos de ensino e de aprendizagem mais democráticos e significativos, a partir de três categorias analíticas: (i) antecedentes; (ii) estratégias; e (iii) projeções. Sem ortodoxia nas definições, mas com enquadramento epistemológico crítico e interdisciplinar, problematiza-se complementarmente a institucionalização da $\mathrm{EaD}$ no espectro universitário público, em vistas a acionar possibilidades de qualificá-la em seu espaço-tempo. Como metodologia, adota-se uma abordagem qualitativa, aplicando-se a técnica de pesquisa documental e bibliográfica, resultando em uma incursão descritiva e exploratória acerca do tema, em caráter ensaístico. Como resultado, compreende-se que a gestão democrática e com referenciamento social pode impactar positivamente processos de ensino e aprendizagem na modalidade $\mathrm{EaD}$, oferecendo subsídios materiais, formativos e tecnológicos à comunidade escolar. Com isso, são oferecidas reflexões necessárias e urgentes acerca do modus operandi da gestão da EaD no contexto brasileiro, abrindo-se modos outros de pensar.

Palavras-chave: Gestão. Educação a Distância. Políticas educacionais. Universidade Aberta do Brasil. Pandemia de covid-19.

1 Doutor em Educação em Ciências (UFRGS). Professor no Instituto de Física e no Programa de Pós-Graduação em Ensino de Física (UNB). Líder do Grupo de Pesquisa em Ensino de Ciências e seus dispositivos: sujeitos, saberes, práticas, discursos e políticas. Brasil. E-mail: marcellof@unb.br

2 Doutor em Letras (USP). Membro da equipe multidisciplinar do Centro de Educação a Distância (UNB). Grupo de Estudos Linguísticos do Estado de São Paulo (GEL). Brasil. E-mail: marcosrmcosta15@gmail.com

3 Doutor em Educação (UFMG). Professor no Departamento de Educação (UFSCar). Líder do Grupo de Estudos e Pesquisas sobre Inovação em Educação, Tecnologias e Linguagens (Grupo Horizonte). Brasil. mill@, ufscar.br. 


\title{
NECESSARY AND URGENT REFLECTIONS ON DE MANAGEMENT OF DISTANCE EDUCATION IN BRAZIL
}

\begin{abstract}
Since the 1990s, the development and amplification of digital information and communication technologies (TDIC) in educational processes and a world phenomenon, certainly associated with the advances of comprehensive models of human cognition in digital culture, plus, above all, embedded in economic totality neoliberal matrix. The imperatives of social distancing linked to the Covid-19 pandemic, set off in 2020, catalyzed diversified forms of education in person in Brazil, including in Basic Education. Observing the respective impacts, but, above all, their determinations, it aims to discuss the management of one of their peculiar forms - to Distance Education (DE) -, seeking to establish categories and reflections that can explain and contradict associated practices, whether they are traditionalized, whether they are contingent. Among the various structural and pedagogical aspects to which DE is related, it is necessary to discuss the elements of management that mobilize, in Brazil, the implementation of more democratic and meaningful teaching and learning processes, based on three analytical categories: (i) background; (ii) strategies; and (iii) projections. Without orthodoxy in the definitions, but with a critical and interdisciplinary epistemological framework, the institutionalization of distance education in the public university spectrum is additionally problematized, with a view to triggering possibilities of qualifying it in its space-time. As a methodology, a qualitative approach is adopted, applying it to a documentary and bibliographic research technique, resulting in a descriptive and exploratory incursion on the subject, in an essay character. As a result, we understand that democratic management and social reference can positively impact teaching and learning processes in the DE, offering material, training and technological subsidies to the school community. As such, we have offered necessary and urgent reflections on the modus operandi of the DE management in the Brazilian context, opening up other ways of thinking.
\end{abstract}

Keywords: Management. Distance Education; Educational policies. Universidade Aberta do Brasil. Covid-19 pandemic.

\section{REFLEXIONES NECESARIAS Y URGENTES SOBRE LA GESTIÓN DE LA EDUCACIÓN A DISTANCIA EN BRASIL}

\section{RESUMEN:}

Desde la década de los noventa, el desarrollo y amplificación de las Tecnologías Digitales de la Información y la Comunicación (TDIC) en los procesos educativos es un fenómeno mundial, ciertamente asociado a avances en modelos integrales de cognición humana en la cultura digital, pero, sobre todo, imbricado con la totalidad económica neoliberal. matriz. Los imperativos del distanciamiento social vinculados a la pandemia Covid-19, que comenzó en 2020, catalizaron formas diversificadas de educación no presencial en Brasil, incluida la Educación Básica. Observando los impactos respectivos, pero, sobre todo, sus determinaciones, el objetivo es discutir la gestión de una de sus formas peculiares - la Educación a Distancia (EaD) -, buscando señalar categorías y reflexiones que puedan explicar y contradecir las prácticas asociadas, ya sea están tradicionalizados, sean contingentes. Entre los diversos aspectos estructurales y pedagógicos con los que se relaciona la $\mathrm{EaD}$, esta discusión se centra en los elementos de gestión que movilizan, en el modelo brasileño, la implementación de procesos de enseñanza y aprendizaje más democráticos y significativos, a partir de tres categorías analíticas: (i) antecedentes; (ii) estrategias; y (iii) proyecciones. Sin ortodoxia en las definiciones, pero con un marco epistemológico crítico e interdisciplinario, se problematiza la institucionalización de la educación a distancia en el espectro universitario público, para activar posibilidades de calificarla en su espacio-tiempo. Como metodología se adopta un enfoque cualitativo, aplicando la técnica de la investigación documental y bibliográfica, resultando en una incursión descriptiva y exploratoria sobre el tema, con carácter ensayístico. Como resultado, se entiende que la gestión democrática y la referencia social pueden impactar positivamente los procesos de enseñanza y aprendizaje en la modalidad de educación a distancia, ofreciendo subsidios materiales, formativos y tecnológicos a la comunidad escolar. Así, se ofrecen reflexiones necesarias y urgentes sobre el modus operandi de la gestión de la educación a distancia en el contexto brasileño, abriendo otras formas de pensar.

Palabras clave: Gestión; Educación a distancia. Políticas educativas. Universidade Aberta do Brasil. Pandemia de covid-19. 


\section{Introdução}

Desde a década de 1990, o desenvolvimento e a amplificação de Tecnologias Digitais da Informação e Comunicação (TDIC) em processos educacionais é um fenômeno mundial, certamente associado aos avanços de modelos compreensivos da cognição humana na cultura digital, marcada pela hiperconectividade e por inteligências coletivas (LÉVY, 1999), mas, sobretudo, imbricado à totalidade econômica de matriz neoliberal (DARDO; LAVAL, 2016). A pandemia de Covid-19, deflagrada em 2020, catalisou transformações profundas em diversos aspectos sociais, culturais, econômicos e, sobretudo, educacionais. Cerca de $80 \%$ dos estudantes do mundo - o que equivale a mais de um bilhão de crianças e adolescentes - foi, direta e indiretamente, afetado pela suspensão das aulas presenciais, segundo a Organização das Nações Unidas para a Educação, a Ciência e a Cultura (Unesco). Como explicam Costa e Sousa (2020a; 2020b), a principal alternativa foi a adoção de formas diversificadas de ensino não presencial, dentre as quais a Educação a Distância (EaD).

Rigorosamente, ainda que subsumida a amplitude de concepções presentes no ordenamento jurídico e na literatura especializada brasileiros, a EaD é uma conjunção teórico-metodológica mais específica e restrita do que o multifacetado ensino não presencial. De fato, a EaD é uma modalidade educacional cuja mediação pedagógica em diversos espaçostempos ocorre por polidocência (professores, tutores e equipes multidisciplinares), a partir de formação própria, com uso de TDIC e materiais didáticos, eventual utilização de estruturas presenciais, e por meio de sistemas próprios de concepção, planejamento, gestão e avaliação (FERREIRA; CARNEIRO, 2015; BRASIL, 2017; MILL, 2018). Tal estruturação, portanto, não se limita às relações espaciais de interação, razão pela qual a tomamos e analisamos como possível (mas não único) desdobramento do vasto feixe de possibilidades de ensino e de aprendizagem ditos "remotos". Seja como for, a EaD é bastante representativa e ilustrativa da grande categoria de ensino/educação mediada por TDIC, pelo que é tomada como objeto neste ensaio. A EaD é, portanto, uma modalidade educacional que abrange diferentes configurações pedagógicas e metodológicas, inclusive as formas "remotas", "emergenciais" e "não presenciais" denominadas nesta pandemia.

Uma outra razão para isso é a abrangência que a modalidade tem tido na educação brasileira - mais recentemente, na educação básica, onde fora historicamente pouco regulada, em relação à educação superior, cuja previsão legal remonta a meados da década de 1990 e a normatização, à década seguinte. De acordo com a Lei n ${ }^{\circ}$ 14.040, de 18 de agosto de 2020, que estabelece normas educacionais excepcionais a serem adotadas durante o estado de calamidade 
pública - o qual, por sua vez, foi reconhecido pelo Decreto Legislativo $n^{\circ}$ 6, de 20 de março de 2020 (CONGRESSO NACIONAL, 2020):

$\S 4^{\circ} \mathrm{A}$ critério dos sistemas de ensino, no ano letivo afetado pelo estado de calamidade pública referido no art. $1^{\circ}$ desta Lei, poderão ser desenvolvidas atividades pedagógicas não presenciais:

I - na educação infantil, de acordo com os objetivos de aprendizagem e desenvolvimento dessa etapa da educação básica e com as orientações pediátricas pertinentes quanto ao uso de tecnologias da informação e comunicação;

II - no ensino fundamental e no ensino médio, vinculadas aos conteúdos curriculares de cada etapa e modalidade, inclusive por meio do uso de tecnologias da informação e comunicação, cujo cômputo, para efeitos de integralização da carga horária mínima anual, obedecerá a critérios objetivos estabelecidos pelo CNE.

Com a Lei $\mathrm{n}^{\circ} 14.040 / 2020$, a EaD pode ser aplicada em todos os sistemas de ensino federal, estaduais, distrital e municipais, em instituições públicas, privadas, comunitárias e confessionais. Observa-se que a educação infantil, o ensino fundamental e o médio passaram a poder usufruir de TDIC, de forma excepcional e exclusiva, para promover processos de ensino-aprendizagem dos conteúdos curriculares de cada etapa e modalidade, inclusive para efeitos de integralização das cargas horárias mínimas. Essa possibilidade é inédita no cenário educacional brasileiro. Destaca-se que essa legislação foi antecedida por diversas portarias do Ministério da Educação (MEC). A primeira delas foi anunciada na segunda metade de março de 2020, autorizando as escolas a substituir aulas presenciais da educação básica pela modalidade a distância por, apenas, trinta dias. A medida foi prorrogada e outras no mesmo sentido foram publicadas até que cabalmente publicada a Lei $n^{\circ} 14.040 / 2020$.

Antes dessa normativa, a EaD era permitida apenas em alguns casos. Por exemplo, não eram viáveis aulas a distância na educação infantil, nem no ensino fundamental. No ensino médio noturno e diurno, respectivamente, havia limitação de $30 \%$ e $20 \%$ da carga horária total nessa modalidade. Já na Educação Superior, o limite estabelecido era de 40\% da carga horária total dos cursos de graduação presencial, com condições acadêmicas bastantes restritas (apenas instituições e cursos com graus elevados de avaliação poderiam usufruir de tal limite). Na pós-graduação stricto sensu, a regulação pela Coordenação de Aperfeiçoamento de Pessoal de Nível Superior (Capes) ocorreu apenas no ano de 2021, ainda não tendo sido plenamente aprovados os primeiros cursos de mestrado/doutorado em EaD.

Esse panorama - catalisado pelos imperativos de distanciamento social decorrentes da pandemia de Covid-19, deflagrada em 2020 - aponta a necessidade de se estudar o fenômeno 
da expansão da EaD na Educação brasileira. Para tratar do tema, este ensaio (ADORNO, 2003) objetiva discutir a dimensão de gestão da modalidade, observando os respectivos impactos, mas, sobretudo, suas determinações, e buscando apontar categorias e reflexões que possam explicar e contradizer práticas associadas, sejam elas tradicionalizadas, sejam elas contingenciais. Dentre os variados aspectos estruturais e pedagógicos a que $\mathrm{EaD}$ se relaciona, detém-se nesta discussão aos elementos da gestão que mobilizem, no modelo brasileiro, a implantação de processos de ensino-aprendizagem mais democráticos e significativos, a partir de três categorias analíticas: (i) antecedentes; (ii) estratégias; e (iii) projeções.

Sem ortodoxia nas definições, mas com enquadramento epistemológico crítico e interdisciplinar, problematiza-se complementarmente a institucionalização da EaD no espectro universitário público, em vistas a acionar possibilidades de qualificá-la em seu espaço-tempo. Por isso, neste trabalho, compreendemos a aprendizagem significativa, no sentido forjado por Ausubel (1968) e desenvolvido por Ferreira et al. (2020), nos seguintes termos: uma descrição, mas também uma normatização, visando ao desenvolvimento cognitivo a partir da interação estratégica de conhecimentos prévios, materiais instrucionais, sequências didáticas devidamente planejadas e sistemáticas avaliativas. O produto de tal aprendizagem deverá ser sempre uma relação contextual, cultural, produtiva e ressignificava de problemáticas que viabilizem saberes, habilidades, crítica e intervenção.

Por gestão democrática na EaD, Mill, Ferreira e Ferreira (2018), a partir de diversos especialistas (BALDRIDGE, 1971; HARDY; FACHIN, 2000), propõem que a perspectiva não deva obstruir o "[...] ideal de construção de comunidades reais, democráticas e solidárias que compartilhem propósitos e promovam a cooperação como forma e princípio de autonomia, desenvolvimento e liberdade". Isso decorre, porque os supracitados autores sustentam que, como apontam Rothschild e Whitt (1986, apud HALL, 2004), em uma organização democrática, o controle se dá, em última instância, pela coletividade. Com isso, as decisões acontecem no âmbito do coletivo por meio de reuniões de gestores, docentes, apoio técnico, discentes e sociedade civil ou, como sugerem Hardy e Fachin (2000, p. 31) a partir de "[...] complexos sistemas de comissões que tipificam a maioria das universidades [...] [que, em geral, são] descritas como colegiais, políticas, anárquicas ou racionais". É nesse sentido que, neste ensaio, propomos a gestão democrática da EaD.

Como metodologia, adota-se uma abordagem qualitativa, aplicando-se a técnica de pesquisa documental e bibliográfica, resultando em uma incursão descritiva e exploratória acerca do tema, em caráter ensaístico (MARCONI; LAKATOS, 2003). Como resultado, compreende-se 
que a gestão democrática e com referenciamento social pode impactar positivamente processos de ensino-aprendizagem na modalidade $\mathrm{EaD}$, oferecendo subsídios materiais, formativos e tecnológicos à comunidade escolar. Com isso, são oferecidas algumas reflexões necessárias e urgentes acerca do modus operandi da gestão da EaD no contexto brasileiro, abrindo-se modos outros de pensar.

\section{Das categorias}

Não são raras, nem poucas, as preocupações teóricas que circundam a modalidade EaD. Desde sua implantação, houve diversos rumores que ora a menosprezavam, ora a supervalorizavam. Para além dessas discussões comparativas que trabalham na dicotomia presencial/não presencial, propõe-se, aqui, explorar um campo mais analítico e crítico do que propriamente operacional. Para isso, é preciso problematizar e localizar focos de resistência do que de reafirmar certezas ou definições, para além da descrição de modelos de gestão estratégica, pedagógica e da qualidade na EaD, o que tem sido fartamente objeto de discussão especializada (MILL, 2018).

De qualquer forma, como exercício de trazer uma propositura mais estatutária do que seja gestão da $\mathrm{EaD}$, ainda que assumindo a polissemia, debruçamo-nos em três categorias que podem apoiar as condições de existência e também de engenharia de funcionamento desse objeto que é a Gestão da EaD. São elas: i) antecedentes; (ii) estratégias; e (iii) projeções.

i) antecedentes: para abordar a Gestão da $\mathrm{EaD}$, é fundamental refletir que há um conjunto de determinações e contradições que formam a sua totalidade. Esses são percussores que mobilizaram - e ainda ressoam contemporaneamente - um certo projeto formativo. Por isso, não vamos - não é necessário, a nosso ver - abordar a gestão da $\mathrm{EaD}$ de forma genérica e descontextualizada, como um construto, como uma abstração. Isso dificultaria apreender suas nuances, sobretudo em território tão plural e multifacetado como o brasileiro. Com efeito, é precisamente o caminho contrário ao da abstração que tomamos. Isso se ratifica, porque cada campo disciplinar tem teorias, metodologias e epistemes próprias - conhecimentos/teorias, processos e relações de verdade (FOUCAULT, 1972).

Voltando-se aos antecedentes, nota-se a importância que tiveram, no território nacional, as condições de regulação e financiamento, uma vez que elas projetam um certo modelo de EaD - e que, por consequência, estabelecem uma relação da modalidade com o ensino presencial e com os polos presenciais (ALONSO, 2014). Além disso, essas condições financeiras também estabeleceram o tipo e a dosimetria das tecnologias, bem como definiram um certo status 
acadêmico - fator esse que está relacionado ao reconhecimento tanto quanto aos conceitos de qualidade e de preconceito para com a modalidade (CORRÊA; SANTOS, 2009).

Essas condições também direcionaram áreas do conhecimento e regiões geográficas estratégicas, os parâmetros de repartição do fomento público (vejam os editais da UAB, que direcionam e priorizam modelos - cursos nacionais, com materiais pré-fabricados; áreas de cursos; tamanho de ofertas; e localidades). Elas, é preciso fazer notar, também favoreceram a mercantilização do ensino superior via $\mathrm{EaD}$, à medida que desregulamentaram uma série de questões - que não são objeto preliminar deste ensaio, mas que integram e dinamizam a formação complexa do objeto de que trata ${ }^{4}$. Resta claro, portanto, que a EaD - no Brasil e em contexto global - não é um projeto neutro, sem compromissos ideológicos, culturais e, por consequência, teóricos. Por isso, quando se aborda o tema da Gestão da EaD, é preciso considerar ao menos duas qualidades, a saber:

- qualidade política: relacionada à intencionalidade do projeto formativo, questionando-se que sujeito pretende-se formar? Que formação está sendo forjada? E, a partir disso, entender como é possível organizar a gestão da modalidade;

- qualidade formal: associada a metodologias, recursos, instrumentos e indicadores de ensino, de avaliação e de gestão a serem aplicados.

A combinação de qualidade política e de qualidade formal faz aparecer perspectivas investigativas e práticas de Gestão da EaD muito peculiares (MILL; FERREIRA; FERREIRA, 2018). Em outros países, isso ocorre de maneira diferente. Mas, no caso brasileiro, essa conjunção de qualidade política e formal, de projeto e de forma, se estabelece no traço constitutivo do modelo de educação com tecnologias que vem sendo, historicamente, adotado pelas universidades, com muita influência internacional (conferir, por exemplo, os grandes projetos de laboratórios de informática, de computador por aluno etc. e, mais recentemente, a pressão de organismos internacionais sobre nosso sistema de ensino ${ }^{5}$ ). Também há a pressão de políticas de indução e fomento de órgãos, como a Coordenação de Aperfeiçoamento de Pessoal de Nível Superior (Capes), o Conselho Nacional de Desenvolvimento Científico e Tecnológico (CNPq) e fundações estaduais de amparo à pesquisa. Existem, ainda, a pressão das normas do Conselho Nacional de Educação (CNE); das políticas curriculares (Parâmetros Curriculares Nacionais, Diretrizes Curriculares Nacionais da Educação Básica, Base Nacional Curricular Comum, dentre outras);

4 Parte dessas questões são discutidas por Alonso (2014), uma vez que autora aponta dos descaminhos que a instauração da EaD no Brasil percorreu.

5 Coelho, Costa e Mattar (2019) abordam parte desses projetos de incentivo ao uso das tecnologias digitais no Brasil, demonstrando que, para além das tecnologias, é também preciso um envolvimento socioemocional com os recursos tecnológicos. 
e das redes de ensino do País, com suas demandas de formação de professores e condições orçamentárias muito particulares e limitadas.

Essa conjunção também se dá pelas contingências advindas das associações, dos eventos e das próprias revistas científicas. Outros influenciadores desses antecedentes estão associados às práticas de produtividade acadêmica desenvolvidas e incentivadas nos Programas de Pós-graduação, bem como nas formações de professores nas universidades, que, pouco a pouco, moldam um currículo não-oficial, certamente, mais potente do que tudo o que se define nos gabinetes do Ministério da Educação (MEC), nas universidades ou nos centros de pesquisa, sobre a gestão da EaD (SACRISTÁN, 2013).

Os antecedentes, portanto, estão relacionados a como a legislação define $\mathrm{EaD}$, a como as universidades assumem e condicionam a sua atuação em torno dessa definição e das contingências do fomento e da forma como a EaD ocorre, de fato, nos cursos, nos polos e nos grupos de pesquisa. É só a partir disso que é possível tecer alguma noção sobre gestão dessa modalidade, seja no Brasil ou qualquer outro lugar - guardadas as particularidades de cada país ou comunidade.

ii) estratégias: a segunda categoria analítica está pautada na seguinte questão: o que vem sendo mobilizado para se constituir esse objeto que é a gestão da EaD? Para isso, tomamo-la como um sistema estratégico de pensamento, de produção de sentidos e de formação de sujeitos, em um contexto particular: regulação e fomento (privado, público social e o semi-público, ou do tipo organização social endógena, da universidade operacional, pautada em orçamento por contratualização e regime de metas). Isso vai aparecer na Constituição Federal de 1988, nos princípios educacionais de acesso, permanência, qualidade e gestão democrática do ensino público. Está também em outra parte da Carta Magna, especificamente no princípio de autonomia didático-científica, administrativa e de gestão financeira e patrimonial das universidades, com indissociabilidade entre ensino, pesquisa e extensão. Mais tarde, esses princípios são reiterados na Lei de Diretrizes e Bases da Educação Nacional, de 1996, qualificando o conceito de gestão democrática pela existência de órgãos colegiados deliberativos com a participação da comunidade.

Já para a EaD, especificamente, a primeira legislação específica foi o Decreto 5622/2005, que trouxe a indicação de que a modalidade teria uma gestão com traços particulares - ainda sem muita especificidade, associada a noção de desempenho e titulação (que a literatura vai trazer como sistemas próprios de gestão). Essa concepção acaba por ser reforçada no Decreto 9.057/2017, dando ainda mais ênfase ao papel do Estado regulador da EaD, com várias condicionantes sobre como se poderia fazê-la, mas pouco ou nada de contrapartida, de asseguramento da modalidade em termos de fomento, profissionais e infraestrutura. 
Entre o Decreto 5.622 de 2005 e o de 2017, que o substitui, houve o Decreto 5.800/2006, que instituiu a Universidade Aberta do Brasil e, com isso, o modelo da única política pública de $\mathrm{EaD}$, sinteticamente baseado em fomento condicionado a produto (edital, concorrência pelo "melhor preço", termos de compromisso com metas e prazos) $)^{6}$. Mesmo com a instauração da $\mathrm{UAB}$, houve pouco investimento e precarização do trabalho docente (sobretudo, de professores e tutores).

Uma das normativas mais recente sobre a EaD é a Resolução 1/2016 do CNE. Esse documento oficial faz uma aproximação um pouco mais orgânica entre a modalidade e os projetos institucionais das universidades. Todavia, objetivamente, essa legislação, ainda, acaba por reiterar uma hibridização da gestão da EaD no Brasil, uma vez que aponta os seguintes direcionamentos:

- Gestão sistêmica de órgãos centrais e setoriais do governo federal (MEC, CAPES, Inep) responsáveis pela formulação, fomento e avaliação das políticas públicas de indução, estruturação, regulação, supervisão, fomento, manutenção, monitoramento e avaliação dos sistemas de ensino a distância;

- Gestão acadêmico-pedagógica e administrativa, que compete às Instituições de Ensino Superior, envolvendo: elaboração de uma proposta institucional de curso a distância; credenciamento específico para a modalidade de ensino a distância; processo reconhecimento de cursos; seleção e registro discente; produção de material didático; desenvolvimento de tecnologias de mediação; desenvolvimento de disciplinas; logística de oferta de cursos e interação com os polos de apoio presencial; avaliação discente e institucionalização ${ }^{7}$.

As estratégias, então, estão relacionadas com as condições de operação e com a viabilização da gestão da EaD. E, como vimos, essas estratégias estão, por ora, distribuídas de forma generalizada pelos órgãos federativos. Falta, ainda, uma política educacional pública que, de fato, valorize e concretize a EaD com bases sólidas que possam dar continuidade e perenidade à modalidade que, por enquanto, acontece como programa no âmbito das universidades públicas.

iii) projeções: como terceira categoria, propomos a analítico daquilo que se revela, que emana do confronto dialético do objeto de que se fala, mas não qualquer devir. Queremos indicar uma projeção de crítica. Isso é importante para que seja possível vislumbrar outros modos de gestão, para além desse que atualmente vigora. É possível assim perscrutar modos alternativos de funcionamento, com novas maneiras de planejar, organizar, dirigir e avaliar a EaD. Por conseguinte, a perspectiva crítica não é de descontruir, desmotivar ou, simplesmente,

6 A UAB tem como proposta ampliar e interiorizar a oferta de cursos e programas de educação superior, por meio da educação a distância. Para mais informações, consultar o artigo de Costa e Sousa (2020b).

7 A institucionalização da EaD no Brasil é um tema controverso e diversos pontos de vista que, não raras vezes, divergem. Por isso, vamos tratar disso no próximo tópico. Mesmo assim, é preciso dizer que as políticas educacionais nacionais insistem em induzir a efetivação da modalidade, quando essa ainda carece de bases. 
atacar. Longe disso, o prisma que trazemos é o da categoria de projeções como práxis, isto é, como produtividade e potência de intervenção (GRAMSCI, 1981).

Nesse sentido, indagamos: como do nosso espaço - e principalmente do nosso lugar que é o da pesquisa - seria possível legitimar e qualificar formas de gestão da EaD? Formas qualificadas, teórica e metodologicamente, é claro, mas socialmente referenciada? Formas não simplesmente gerencialistas, que buscam uma noção de eficiência pautada no custo e no benefício econômico, mas que vislumbre a equidade, a democracia, a diferença, a decolonialidade. $\mathrm{Na}$ linha de pensamento de Darcy Ribeiro (1975), que tipo de gestão da EaD pode promover esse tipo de relação entre a universidade e o espaço social de que ela faz parte, mas, principalmente, a que ela busca criticar e transformar?

Essa é uma perspectiva muito importante e é a partir dessa tríade, composta por antecedentes, estratégias e projeções, que se poderia formular um estatuto acerca do que é e como se faz gestão da EaD no Brasil.

\section{Proposições}

A partir de categorias analíticas acerca da gestão da EaD, lançadas anteriormente, buscamos oferecer algumas reflexões e proposições com base no modelo brasileiro e numa crítica possível. O primeiro passo requer definir o que seja gestão dessa modalidade. Em poucas palavras, podemos dizer que a Gestão da EaD é uma disposição (um conjunto organizado) de objetivos políticos (estratégicos), sob uma ambiência de regramento, supervisão e fomento (ou financiamento, no contexto privado), que leva a uma compatível organização acadêmica, pedagógica e administrativa de conhecimentos em interface com tecnologias que promovem o ensino-aprendizagem não presencial (MILL, 2018; MILL; FERREIRA; FERREIRA, 2018). Em síntese, está associada a projetos institucionais e de curso, de objetivos de aprendizagem, infraestrutura e relações de mediação (tecnologias, docência e tutoria) para a certificação de estudantes sob certos critérios de qualidade, utilizando um ambiente infotécnico - aplicando um termo de Lévy (1999), seria em um ciberespaço.

No Brasil contemporâneo, esses critérios de qualidade estão estabelecidos no regime de metas e de competências. Isso deverá ser repactuado sob a necessidade urgente (re)pensar a gestão como instrumento de eficiência social, com ampliação de direitos e para a admissão de outros modelos culturais, econômicos e sociais (RIBEIRO, 1975). É isso que nossas projeções aspiram para a gestão da EaD nos anos vindouros. 
Poderíamos questionar: qual seria a importância de pautar a Gestão de sistemas de EaD no contexto atual? Ou, ainda, como a preocupação com uma boa gestão da EaD contribuiria para melhorar o ensino-aprendizagem? Para responder - mas não resolver, de forma absoluta - essas questões, refletimos que a gestão é o operador formal da concretização de uma política pública. Baseamos isso, na seguinte sequência que acompanha, na maioria dos casos, a efetivação de uma política pública em nosso território: 1. Formação da agenda; 2. Formulação da política; 3. Processo de tomada de decisão; 4. Implementação da política; e 5. Avaliação ${ }^{8}$.

Como operador formal, a gestão define prioridades, estratégias e qualidade. Se estivermos atentos a essa potência, a qualidade do ensino e da aprendizagem podem ser pensadas sob agendas e critérios mais sociais, pautadas em uma racionalidade menos tecnicista e mais crítica - na perspectiva que discutimos no tópico anterior. Por isso, a gestão da EaD pode melhorar os processos de ensino-aprendizagem quando enfatiza o bem-estar dos que utilizam os equipamentos, os serviços e os recursos e não necessariamente se foca na efetividade da gestão dos equipamentos, dos serviços e dos recursos. Não se tratar de ignorar princípios de eficiência da administração, mas de referenciá-los por critérios sociais e não meramente econômicos, como tem imperado o modelo gerencialista brasileiro (vide, por exemplo, a lógica de pactuação de fomento a políticas públicas educacionais amplamente praticada pelos órgãos federais - em todas as áreas e na $\mathrm{EaD}$, em particular -, pautada pelo regime de concorrência em editais, oferta de serviços pelo menor preço, precarização de condições e, por consequência, da qualidade).

Além disso, sabemos que um dos principais pontos da discussão sobre a gestão da EaD é o processo de institucionalização da modalidade. Para tratar desse tema, não podemos ser simples, nem simplórios na concepção do que é a institucionalização de uma modalidade educacional, principalmente considerando as diversas realidades socioculturais e econômicas de um país como o Brasil que tem proporções continentais e problemas sociais igualmente relevantes. Primeiro, é bom pactuarmos uma noção sobre o que seja institucionalização. No senso comum, é usual que essa noção seja a de adaptação da EaD ao modelo já instituído - no caso, o presencial - ou, ainda, de imposição da EaD a uma cultura universitária tradicionalmente presencial. Diante disso, é imprescindível refutar algumas hipóteses para se entender o conceito, sobretudo dizendo o que a institucionalização da EaD não é.

A institucionalização da $\mathrm{EaD}$ não é adaptação (apenas) e também não é um embate maniqueísta de fazer valer a presença de uma modalidade em detrimento de outra (FERREIRA; CARNEIRO, 2015; FERREIRA; NASCIMENTO; MILL, 2018). A propósito, é preciso também 
desmistificar essa visão romântica que muitas vezes prevalece sobre a $\mathrm{EaD}$, na qual se quer idealizar uma modalidade universal no sentido de que todos podem ter acesso a qualquer hora e em qualquer lugar - sabemos, sobretudo agora no momento pandêmico, que não é bem assim! Há muita controvérsia, muitos problemas estruturais e muita racionalidade no modelo brasileiro, principalmente o que vigora na UAB. Por isso, é premente que sejamos mais críticos, no sentido de observarmos outros modos de se fazer e se apresentar esse modelo.

Feitas essas ressalvas, pensando a institucionalização da EaD no modelo universitário brasileiro, poderíamos dizer que, aqui, houve uma conformação - trazendo a ideia de plasticidade e não de mera acomodação - da organização das contingências internas e externas, envolvendo a cultura (normas formais e informais), a estrutura (hierarquias, fluxos e tamanho), as tecnologias e o pessoal (características e formação). Uma universidade pública, tipicamente, é uma burocracia altamente especializada, com alto grau de disseminação do poder decisório e colegialidade (FERREIRA; NASCIMENTO; MILL, 2018). Por isso, só se pode falar em institucionalização considerando esses aspectos. Para universidade pública, institucionalizar não é padronizar. Em nosso ponto de vista, institucionalizar é reconhecer, legitimar e posicionar no sistema estratégico de poder, saber e subjetividade (FOUCAULT, 1979).

Outro aspecto importante sobre a institucionalização é que ela é um processo, e não um elemento binário, do tipo sim ou não. Por isso, há uma graduação e, nesse sentido, se pode dizer que existem níveis ou graus de institucionalização. É uma ação com influência externa, mas sobretudo endógena, que só faz sentido quando resgatamos a função social da universidade, como produtora e disseminadora de conhecimentos e de críticas aos modelos econômicos, sociais e culturais, com autonomia e indissociabilidade entre ensino, pesquisa e extensão (RIBEIRO, 1975).

Diante dessa reflexão, uma pergunta pertinente é: qual seria a relação disso com a Gestão da EaD? Apresentamos, aqui, um modelo teórico que pensa a institucionalização da EaD por cinco dimensões e alguns indicadores. Essas dimensões estão associadas à gestão da $\mathrm{EaD}$ e são as seguintes: (i) planejamento, (ii) organização, (iii) infraestrutura, (iv) pessoal e (v) serviços discentes (FERRREIRA; CARNEIRO, 2015; FERREIRA; NASCIMENTO; MILL, 2018). A seguir, definimos e damos alguns indicadores em cada uma dessas dimensões:

Planejamento: visão e projeção institucional, representatividade nos órgãos colegiados, orçamento e avaliação permanente como política institucional;

Organização: abrangência, reconhecimento e legitimidade da $\mathrm{EaD}$ - da sua gestão e nas unidades acadêmicas; qualidade e sustentabilidade do modelo;

Infraestrutura: condições tecnológicas, espaços físicos, sistemas de gestão, modelo de EaD (Design Instrucional, produção de materiais), apoio técnico e 
formação de equipes;

Pessoal: reconhecimento formal (carga horária, progressões) e incentivo financeiro (não apenas por bolsas, como ocorre em diversos programas), qualidade das equipes de gestão, administrativa e multidisciplinar e qualidade da mediação pedagógica (docência e tutoria);

Serviços aos estudantes: além do acompanhamento pedagógico, pressupõe-se acesso a acervo bibliográfico e bases, participação em colegiados, suporte técnico, acessibilidade, assistência estudantil (moradia, Restaurante Universitário, bolsas de iniciação à docência e à pesquisa científica, bem como bolsas para ações de extensão). Enfim, garantir direitos que deveriam ser óbvios incontestáveis, mas não o são.

Como se pode observar, a gestão da EaD está, intrinsecamente, conectada à institucionalização da modalidade, porque, sendo institucionalizada - mesmo que gradualmente, como indicamos - as dimensões propostas acima seriam, paulatinamente, efetivadas, o que contribuiria para os respectivos processos de gestão. É um circuito em que cada uma das dimensões se inter-relaciona com a outra e, assim, dá viabilidade e adequação ao processo.

\section{Considerações finais}

O objetivo deste ensaio foi discutir a gestão EaD em perspectiva crítica, apontando categorias e reflexões que possam alinhar as práticas diversamente aplicadas no território nacional. Para isso, em um primeiro tópico, lançamos três categorias para repensar o modelo brasileiro de gestão de EaD. No tópico seguinte, foram discutidas proposições acerca da definição do conceito de gestão de EaD e de sua função social, culminando com uma proposição teórica de cinco dimensões para a institucionalização da $\mathrm{EaD}$ - pensada em uma gradação de níveis de institucionalização.

Os desafios da $\mathrm{EaD}$ são muitos, certamente agravados por este momento pandêmico que assola o mundo e, ainda mais drasticamente, sistemas políticos incipientes e condições socioeconômicas precárias, como é o caso do Brasil. Mesmo assim, é necessário discutir as políticas de fomento e gestão da $\mathrm{EaD}$ no território nacional, sobretudo a dependência do fomento externo combinada com a fragilidade da política pública (descontinuidade, precariedade de parâmetros e a questão docente). Por isso, não tratamos de todos os meandros que constituem e tecem o conceito de gestão da $\mathrm{EaD}$ e de sua prática. O propósito que traçamos - e esperamos ter alcançado - foi de articular reflexões necessárias e urgentes para o campo de estudo. 
O desafio central das universidades que ofertam $\mathrm{EaD}-\mathrm{e}$, particularmente, que acolhem os editais da UAB - é o de qualificar o debate e posicionar a modalidade na indissociabilidade das outras ações da instituição no tripé ensino-pesquisa-extensão. Somente assim a institucionalização da $\mathrm{EaD}$ seria estrategicamente desenvolvido, porque em sintonia com as outras ações da organização, deixando de ser - como ainda o é em não raras instituições de ensino superior - um penduricalho, alheio às outras ações, mormente uma fonte de captação de recursos, e, por vezes, dispensável.

Na perspectiva foucaultiana com a qual nos comprometemos, o que trazemos à luz neste ensaio é uma forma de (re)pensar a gestão da EaD. Existem, em franco desenvolvimento, diversas linhas de pesquisa que estão explorando esse campo já algum tempo. Por exemplo, Rumble (2003) traz uma visão crítica dos atuais sistemas de gestão da EaD. Polak (2002) traz uma excelente explicação sobre a estrutura e o funcionamento dos sistemas de ensino na modalidade EaD. Mais recentemente, como trouxemos à luz em diversos momentos deste trabalho, as contribuições de Mill (2018) e Ferreira, Nascimento e Mill (2018) exploram esse tema em diversas facetas (pedagógica, financeira, institucional, da qualidade etc.). Esses são apenas alguns dos estudos que indicam a importância de se continuar examinar esse tema, bem como demonstram sua relevância para o desenvolvimento da EaD no Brasil e no mundo.

Por fim, enfatiza-se que a dependência da gestão da EaD é menos do gestor e mais das dimensões institucionais de planejamento, organização, infraestrutura, pessoal e serviços, como apresentamos. A gestão deverá ser mais democrática, tanto mais criticamente refletida, como prevê a legislação vigente (Constituição federal; LDB, Diretrizes Curriculares Nacionais da Educação Básica, dentre outros documentos). Uma gestão da EaD de fato qualificada, a nosso ver, é aquela que consegue mobilizar e organizar processos e recursos na direção de ampliar o nível de institucionalização, ou seja, de perseguir esses indicadores sempre com referência social. Por conseguinte, do capital ao social, é o percurso que prevemos para a gestão democrática da EaD.

\section{Referências}

ADORNO, Theodor. Ensaio como forma. In: ADORNO, Theodor. Notas de literatura I. Tradução de Jorge de Almeida. São Paulo: Editora 34, 2003, p. 15 -45.

ALONSO, Katia Morosov. A EaD no Brasil: sobre (des)caminhos em sua instauração. Educar em Revista, Curitiba, Edição Especial, n. 4, p. 37-52, 2014.

BRASIL. Decreto $\mathbf{n}^{\mathbf{0}} \mathbf{9 . 0 5 7}$, de 25 de maio de 2017. Regulamenta o art. 80 da Lei $\mathrm{n}^{\mathbf{0}}$ 9.394, de 20 de dezembro de 1996, que estabelece as diretrizes e bases da educação nacional. 2017. Disponível em: https://www.in.gov.br/materia/-/asset_publisher/Kujrw0TZC2Mb/content/ id/20238603/do1-2017-05-26-decreto-n-9-057-de-25-de-maio-de-2017-20238503 Acesso em: 
15 out. 2021.

BRASIL. Lei $\mathbf{n}^{\mathbf{0}} \mathbf{1 4 . 0 4 0}$, de 18 de agosto de 2020. Estabelece normas educacionais excepcionais a serem adotadas durante o estado de calamidade pública reconhecido pelo Decreto Legislativo ${ }^{0}$ 6, de 20 de março de 2020; e altera a Lei ${ }^{\circ} 11.947$, de 16 de junho de 2009. 2020. Disponível em: https://www.in.gov.br/en/web/dou/-/lei-n-14.040-de-18-de-agostode-2020-272981525 Acesso em: 15 out. 2021.

BALDRIDGE, J. Victor. Power and conflict in the university. London: Wiley, 1971.

COELHO, Patrícia Margarida Farias; COSTA, Marcos Rogério Martins; MATTAR, João Augusto. Saber Digital e suas Urgências: reflexões sobre imigrantes e nativos digitais. Educação \& Realidade, Porto Alegre, v. 43, n. 3, p. 1077-1094, jul./set. 2018.

CONGRESSO NACIONAL. Decreto legislativo $\mathbf{n}^{\mathbf{0}} \mathbf{6}$, de 2020. Reconhece, para os fins do art. 65 da Lei Complementar $n^{\circ} 101$, de 4 de maio de 2000, a ocorrência do estado de calamidade pública, nos termos da solicitação do Presidente da República encaminhada por meio da Mensagem $n^{\circ}$ 93, de 18 de março de 2020. 2020. Disponível em: http://www.planalto.gov.br/ ccivil_03/portaria/DLG6-2020.htm Acesso em: 15 out. 2021.

CORRÊA, Stevan de Camargo; SANTOS, Larissa Medeiros Marinho dos. Preconceito e educação a distância: atitudes de estudantes universitários sobre os cursos de graduação na modalidade a distância. Educação Temática Digital, Campinas, v. 11, n.1, p. 273-297, 2009.

COSTA, Marcos Rogério Martins; SOUSA, Jonilto Costa. Desafios da Educação e das Tecnologias de Informação e Comunicação durante a pandemia de Covid-19: problematizando a transmissão de aulas assíncronas nos canais de televisão aberta e o uso da internet para fins didático-pedagógicos. Revista Com Censo: Estudos Educacionais do Distrito Federal, Brasília, v. 7, n. 3, p. 55-64, ago. 2020a.

COSTA, Marcos Rogério Martins; SOUSA, Jonilto Costa. Educação a Distância e Universidade Aberta do Brasil: reflexões e possibilidades para o futuro pós-pandemia. Revista Thema, Pelotas, v. 18, n. Especial, p. 124-135, 2020 b.

DARDOT, Pierre; LAVAL, Christian. A Nova Razão do Mundo: Ensaio sobre a sociedade neoliberal. São Paulo: Editora Boitempo, 2016.

FERREIRA, Marcello; CARNEIRO, Teresa Cristina Janes. A institucionalização da educação a Distância no Ensino Superior Público Brasileiro: análise do Sistema Universidade Aberta do Brasil. Educação Unisinos, São Leopoldo, v. 19, n. 2, p. 228-242, maio/agosto 2015.

FERREIRA, Marcello; NASCIMENTO, João Paulo Rodrigues; MILL, Daniel. Institucionalização da Educação a Distância. In: MILL, Daniel. (Org.). Dicionário Crítico de Educação e Tecnologias e de Educação a Distância. Campinas: Papirus, 2018. p. 359-363.

FERREIRA, Marcello et al. Unidade de Ensino Potencialmente Significativa sobre óptica geométrica apoiada por vídeos, aplicativos e jogos para smartphones. Revista Brasileira de Ensino de Física, v. 42, e20200057, p. 1-13, 2020.

FOUCAULT, Michel. A Arqueologia do saber. Tradução de Luiz Felipe Baeta Neves, revisão de Ligia Vassalo. Petrópolis: Vozes, Lisboa: Centro do Livro Brasileiro, 1972. 
FOUCAULT, Michel. Microfísica do poder. Tradução de Roberto Machado. Rio de Janeiro: edições Graal, 1979.

GRAMSCI, Antonio. A concepção dialética de história. Tradução de Carlos Nelson Coutinho. 4 ed. Rio de Janeiro: Civilização Brasileira, 1981.

HARDY, Cynthia; FACHIN, Roberto. Gestão estratégica na universidade brasileira. 2. ed., Porto Alegre: EdUFRGS, 2000.

HALL, Richard. Organizações, estruturas, processos e resultados. 8. ed. São Paulo: Prentice Hall, 2004.

LÉVY, Pierre. Cibercultura. Tradução de Carlos Irineu da Costa. São Paulo: Ed. 34, 1999.

MARCONI, Marina de Andrade; LAKATOS, Eva Maria. Fundamentos de metodologia científica. 5 ed. São Paulo: Atlas, 2003.

MILL, Daniel. (org.). Dicionário crítico de educação e tecnologias e de educação a distância. Campinas: Papirus, 2018.

MILL, Daniel; FERREIRA, Marcello; FERREIRA, Deise Mazzarella Gourlart. Gestão da Educação a Distância na universidade pública como campo de disputa: da instituição social à academia líquida. Revista Brasileira de Política e Administração da Educação, Brasília, v. 34, n. 1, p. 143-166, 2018.

OLIVEIRA, Djalma de Pinho Rebouças de. Planejamento estratégico. São Paulo: Atlas, 2007.

POLAK, Ymiracy Nascimento. Gestão, estrutura e funcionamento da educação a distância. Curitiba: IBPEX, 2002.

RIBEIRO, Darcy. A universidade necessária. Rio de Janeiro: Paz e Terra, 1975.

RUMBLE, Greville. A gestão dos sistemas de Educação a Distância. Brasília: Editora UnB: Unesco, 2003.

SACRISTÀN, José Gimeno. O que significa o currículo? In: SACRISTÀN, José Gimeno (Org.). Saberes e incertezas sobre o currículo. Porto Alegre: Penso, 2013. p. 16-35.

Recebido em: 10 de outubro de 2021

Publicado em: 06 de dezembro de 2021. 